\title{
Evaluation and projection of summer extreme precipitation over East Asia in the Regional Model Inter-comparison Project
}

\author{
Fu-Ting Wu ${ }^{1,2}$, Shu-Yu Wang ${ }^{1,2, *}$, Cong-Bin Fu' ${ }^{1,2}$, Yun Qian ${ }^{3}$, Yang Gao ${ }^{3}$, \\ Dong-Kyou Lee ${ }^{4}$, Dong-Hyun Cha ${ }^{5}$, Jian-Ping Tang ${ }^{1}$, Song-You Hong ${ }^{6}$ \\ ${ }^{1}$ Institute of Climate and Global Change Research \& School of Atmospheric Sciences, Nanjing University, Nanjing 210023, \\ PR China \\ ${ }^{2}$ Jiangsu Collaborative Innovation Centre for Climate Change, Nanjing 210023, PR China \\ ${ }^{3}$ Atmospheric Science and Global Change Division, Pacific Northwest National Laboratory, Richland, Washington 99352, USA \\ ${ }^{4}$ School of Earth and Environmental Sciences, Seoul National University, Seoul 151742, Korea \\ ${ }^{5}$ School of Urban and Environmental Engineering, Ulsan National Institute of Science and Technology, Ulsan 689798, Korea \\ ${ }^{6}$ Korea Institute of Atmospheric Prediction Systems, Seoul 07071, Korea
}

\begin{abstract}
This study assesses the ability of 4 regional climate models (RCMs) from the Regional Model Inter-comparison Project (RMIP) and their regional multi-model ensemble, as well as their driving global climate model ECHAM5, to reproduce the summer extreme precipitation conditions in the years 1982 to 2000 and to project future (2052 to 2070) change over East Asian land areas under an A1B emission scenario. The results show that all models can adequately reproduce the spatial distribution of extreme heavy precipitation (R95P) with high spatial correlation $(>0.8)$. However, they do not perform well in simulating summer consecutive dry days (CDD). The ensemble average of multi-RCMs substantially improve model capability to simulate summer precipitation in both total and extreme categories when compared to each individual RCM. For individual RCMs, the spread of regional differences is assessed by bias distribution. The RegCM3 model simulates less extreme precipitation, in agreement with ECHAM5. This is probably due to the lack of an internal nudge process. Composite analysis of large-scale water vapor transport and geopotential height indicate that simulated R95P biases are associated with a deficiency in capturing the low-level field. For the projection of extreme wet and dry conditions under A1B emissions, most of the models predict an overall increase in heavy precipitation and CDD over East Asia, which will enhance the risk of drought disasters in the future.
\end{abstract}

KEY WORDS: Regional Model Inter-comparison Project - RMIP - Regional climate model · Extreme precipitation · Consecutive dry days · Evaluation and future projection · East Asia

Resale or republication not permitted without written consent of the publisher

\section{INTRODUCTION}

Compared to mean climate conditions, extreme climate and weather are more likely to lead to major disasters. Consecutive periods of little or no precipitation can cause water shortages and drought, while heavy precipitation, which often happens in a short period such as torrential rain, may cause flooding and soil erosion ( $\mathrm{Wu} \& \mathrm{Fu}$ 2013). An increase in extreme precipitation has been widely reported from both observations and model simulations under global warming circumstances (Zhai et al. 1999, Gao et al. 2008, Lang \& Sui 2013, Wu \& Fu 2013, Ji \& Kang 2015). Moreover, ever-increasing temperatures re- 
sulting from greenhouse gas emission have been reported to exacerbate precipitation intensity (Trenberth et al. 2003, Liu et al. 2009). As a result, more reliable projection of future climate changes, especially the extremes and their regional impacts, is crucial for long-term planning at national and regional scales for the adaptation to and mitigation of climate change in the future.

Global climate models (GCMs) are suitable tools for the assessment and projection of climate change. However, they are not necessarily able to capture detailed mesoscale processes due to coarse resolution (Giorgi \& Mearns 1999). By contrast, regional climate models (RCMs) have shown superiority in reproducing the regionally detailed climate forced by regional components, such as topography, lakes, coastline, and land-use distributions (Fu et al. 2005, $\mathrm{Yu}$ et al. 2011). Nonetheless, RCMs have many uncertainties due to boundary-initial conditions, spatial resolution, and physical process schemes (Gao et al. 2006). As a result, it is essential to evaluate the performance of these models through comparisons with observations before using them as projection tools, due to the uncertainties in model configuration or driving field.

Extensive research has been carried out evaluating the ability of single regional models to simulate the recent climate, driven either by reanalysis data or outputs from GCMs (Gao et al. 2002, 2008, Leung et al. 2004, Qian \& Leung 2007, Lee et al. 2012). However, each model has a configuration that results in different strengths and weaknesses. For instance, the RegCM3 model has been reported to underestimate extreme precipitation over southern China and overestimate light precipitation (Xu et al. 2013). As a result, the application of a set of RCMs with some common points and a systematic examination of their combined uncertainty in simulating recent climate and projecting future climate are needed (Gao et al. 2012, Wu et al. 2015).

Several regional model comparison programs have been established, such as the Coordinated Regional Climate Downscaling Experiment (CORDEX) project (Giorgi et al. 2009, Park et al. 2013, Kim et al. 2014, Park et al. in press), Prediction of Regional scenarios and Uncertainties for Defining European Climate change risks and Effects (PRUDENCE) for Europe (Christensen et al. 2007), the North American Regional Climate Change Assessment Program (NARCCAP) for America (Mearns et al. 2009), and the Regional Climate Model Inter-comparison Project (RMIP) for Asia (Fu et al. 2005). The latter was launched by the System for Analysis, Research and
Training (START) to study the performance of an ensemble of RCMs through simulating the East Asian climate. In this study, we employed 4 RCMs from the RMIP. Previously, Niu et al. (2015) evaluated the simulated mean precipitation from $5 \mathrm{RCMs}$ in the RMIP project. They found that a multi-model ensemble could improve the performance of the driving GCM in reproducing recent summer mean precipitation despite inter-model spread. Nevertheless, a systematic quantitative evaluation of RCMs in the RMIP project in terms of their capabilities in reproducing summer climate extremes, such as intensities, durations or frequencies, has not been undertaken.

This study aimed to evaluate the performance of the RCMs in simulating current precipitation extremes and projecting future change in terms of several extreme indices over the East Asian region.

\section{DATA AND METHODOLOGY}

\subsection{Models}

In this study, results from 4 RCMs in the RMIP project were used to assess the ability of the RCMs to simulate precipitation extremes and to project the future changes over Monsoon Asia, which was defined as the area lying within 0 to $55^{\circ} \mathrm{N}$ and 72 to $150^{\circ} \mathrm{E}$ (Fig. 1). The 4 RCMs were: the Regional Climate Model version 3 (Pal et al. 2007), which was developed at the Abdus Salam International Center for Theoretical Physics (ICTP-RegCM3, hereafter RegCM3) without nudging; the Weather Research and Forecasting model (WRF) using the rapid radiative transfer model (RRTM) radiation scheme, based on an MM5 mesoscale model performed at Pennsylvania State University (Skamarock et al. 2005); the Seoul National University Regional Climate Model (SNURCM), based on an MM5 mesoscale model (Lee et al. 2013); and the Global/Regional Integrated Model system (GRIMs) from Yonsei University (Hong et al. 2013).

Table 1 lists configurations of the 4 RCMs used in this study and the details of their dynamics and physical parameterizations. All RCMs were driven by the coupled atmosphere-ocean general circulation model (AOGCM) output of the European CentreHamburg model version 5/Max Planck Institute Ocean Model (ECHAM5/MPI-OM, simplified as ECHAM5) to provide the initial and boundary conditions (Roeckner et al. 2003). Studies have shown that ECHAM5 can largely reproduce present climates (Bengtsson et al. 2007, Feng et al. 2011) and the vari- 


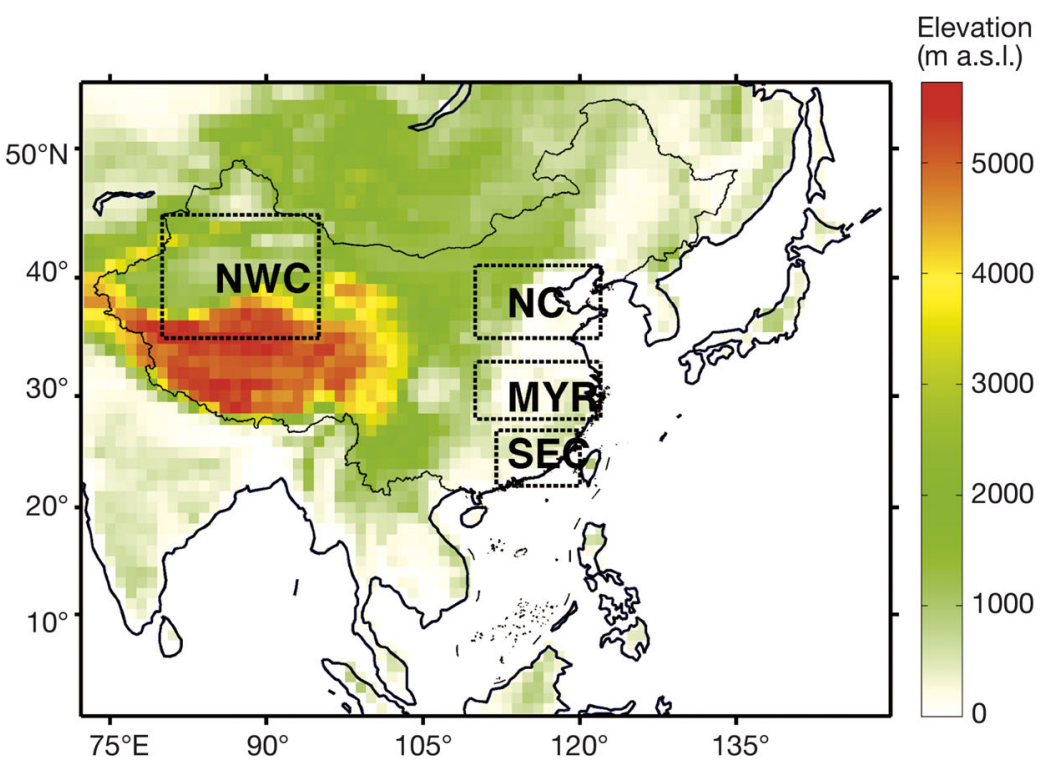

Fig. 1. Domain and topography $(\mathrm{m})$ for the Regional Model Inter-comparison Project (RMIP) as represented by the APHRO (Asian Precipitation-Highly-Resolved Observational Data Integration towards Evaluation of the Water Resources) project region. The 4 regions analyzed in detail are illustrated by black boxes: North China (NC: 35 to $41^{\circ} \mathrm{N}, 110$ to $122^{\circ} \mathrm{E}$ ); mid-lower Yangtze River basin (MYR: 28 to $33^{\circ} \mathrm{N}, 110$ to $122^{\circ} \mathrm{E}$ ); southeast China (SEC: 22 to $27^{\circ} \mathrm{N}, 112$ to $120^{\circ} \mathrm{E}$ ); northwest China (NWC: 35 to $45^{\circ} \mathrm{N}, 80$ to $95^{\circ} \mathrm{E}$ ). a.s.l.: above sea level

ability of Asian-Australian monsoon precipitation (Zhou et al. 2009). This GCM model had a spatial resolution of approximately $1.875^{\circ} \times 1.875^{\circ}$ with $31 \mathrm{lev}-$ els. To facilitate inter-comparison among models, all simulation results were interpolated to $0.5^{\circ} \times 0.5^{\circ}$ over the East Asian area. All RCMs were run over 2 periods: 1978 to 2000 as a reference for recent climate (20th century) and 2038 to 2070 for future climate projection under the Special Report on Emis- sions Scenarios (SRES) A1B emission scenario. The first 2 yr of each simulation period were considered as spinup time. To facilitate the assessment of precipitation change at seasonal scales, we chose 2 time slices: 1982 to 2000 for control climate and 2052 to 2070 for future climate. In this study, only the model data for precipitation over the land area were used.

\subsection{Observation data}

Gridded precipitation data from the Asian Precipitation-Highly-Resolved Observational Data Integration towards Evaluation of the Water Resources (APHRODITE's Water Resources, hereafter referred to as APHRO) was used to validate the simulation results (Yatagai et al. 2009). This dataset has been used extensively for precipitation analyses in the past (Gao et al. 2011, Zou \& Zhou 2013). It is a long-term gridded continental-scale product that merges quite dense networks of rain gauge records over Asia (www. chikyu.ac.jp/precip/index.html). Studies have shown that this dataset can generally capture climatology patterns, but it has underestimated precipitation intensity and overestimated precipitation frequency over China (Han \& Zhou 2012), especially over the Tibetan Plateau region (Wu \& Gao 2013). Here, we used version 1101R2 over the Monsoon Asia domain

Table 1. Properties of 4 regional climate models (RCMs) participating in the Regional Model Inter-comparison Project (RMIP). ER: exponential relaxation; IPR: implicit perturbation relaxation; FC: Fritsch-Chappell; KF: Kain-Fritsch; SA: simplified Arakawa; SUBEX: subgrid explicit moisture scheme; WSM5: WRF single moment 5-class; YSU: Yonsei University; CCM: community climate model; GSFC: Goddard Space Flight Center

\begin{tabular}{|lllll}
\hline & RegCM3 & WRF & SNURCM \\
\hline Leader & J. P. Tang & J. P. Tang & D. K. Lee & GRIMs \\
Institute & Nanjing University & Nanjing University & Seoul National University & Yonsei University \\
Dynamic process & Hydrostatic & Non-Hydrostatic & Non-Hydrostatic & Hydrostatic \\
Lateral boundary condition & ER & ER & ER & IPR \\
Internal nudging & No & Yes & KF & Yes \\
Convective scheme & FC & KF & Reisner2 & SA \\
Microphysics & SUBEX & WSM5 & NCAR/CLM & Diagnostic \\
Land surface scheme & BATSle & NOAH & CCM2 & YSU \\
Planetary boundary layer scheme & Holtslag & YSU & CCM2 \\
Longwave radiation scheme & CCM3 & RRTM & NASA/GSFC \\
Shortwave radiation scheme & CCM3 & Dudhia & Lee et al. (2013) & Hong et al. (2013) \\
References & Pal et al. (2007) & Skamarock et al. (2005) & LSFC \\
\hline
\end{tabular}


Table 2. Definitions of precipitation indices used in this paper. Days were defined as rainy when daily rainfall $(r)$ was $\geq 1.0 \mathrm{~mm}$

\begin{tabular}{|c|c|c|c|}
\hline Abbreviation & Name & Definition & Units \\
\hline PRCPTOT & Total wet-day precipitation amount & Total precipitation amount on rainy days ( $r \geq 1.0 \mathrm{~mm})$ & $\mathrm{mm}$ \\
\hline SDII & Simple precipitation intensity index & Daily precipitation amount on rainy days ( $r \geq 1.0 \mathrm{~mm})$ & $\mathrm{mm} \mathrm{d}^{-1}$ \\
\hline R95P & Very wet day precipitation amount & Accumulated precipitation amounts when $r \geq 95$ th percentile & $\mathrm{mm}$ \\
\hline R95T & Contribution of R95P to the total & Percentage of total precipitation on rainy days made up by R95P & $\%$ \\
\hline CDD & Maximum length of dry spell & Maximum number of consecutive days with $r<1.0 \mathrm{~mm}$ & $\mathrm{~d}$ \\
\hline
\end{tabular}

for comparison with model-produced precipitation. Data used in this study cover the entire Monsoon Asia area at a horizontal resolution of $0.5^{\circ} \times 0.5^{\circ}$ for the overlapped period.

\subsection{Indices}

To evaluate the performance of RMIP models in simulating extreme climate, 5 indices from the Expert Team on Climate Change Detection, Monitoring and Indices (ETCCDMI; http://etccdi.pacificclimate. org/list_27_indices.shtml) were adopted (Table 2). According to the ETDDCMI, days are defined as rainy when daily rainfall $(r)$ is $\geq 1.0 \mathrm{~mm} \mathrm{~d}^{-1}$. PRCPTOT is the accumulated precipitation amount within a period, defined as the total precipitation on rainy days $\left(r \geq 1.0 \mathrm{~mm} \mathrm{~d}^{-1}\right)$. The extreme index, R95P, is defined as the accumulated precipitation amount when daily precipitation is greater than the 95th percentile of rainy days. The maximum number of consecutive dry days (CDD) was employed to characterize the persistence of dry events, the seasonal mean precipitation intensity (SDII) was used to analyze the precipitation intensity, and the 2 similar indices R95P and R95T (percentage of the total precipitation on rainy days made up by $\mathrm{R} 95 \mathrm{P}$ ) were used to investigate the extreme precipitation features (Table 2). In addition, the frequency of occurrence (probability density function, PDF) of the precipitation, defined as the percentage count of the total days that each precipitation category took up, was also used to examine the ability to simulate categories of different intensity over a long time period.

\section{RESULTS}

\subsection{Recent precipitation simulation assessment}

3.1.1. Climatology comparison. The performances of 4 RCMs and 1 driving GCM in simulating extreme summer (June-July-August) average precipitation climatology for 1982 to 2000, as indicated by SDII and R95P, were compared (Fig. 2). Generally, extreme precipitation R95P (bottom panels) showed quite similar spatial patterns to mean precipitation SDII (upper panels). Both precipitation indices were characterized by higher precipitation in eastern and southern China and lower precipitation in western and northern China. All of the RCMs and the GCM could accurately reproduce the wet-to-dry transition zone from the southeast (as much as $16 \mathrm{~mm} \mathrm{~d}^{-1}$ ) to the northwest $\left(<2.0 \mathrm{~mm} \mathrm{~d}^{-1}\right)$ in China. However, RegCM3 showed less evident southeast-northwest variation, simulating less precipitation in southeast China. The percentage of heavy precipitation in total precipitation (R95T) was also compared (not shown). Extremely heavy precipitation (R95P) contributed up to $30 \%$ of the total precipitation over eastern China in summer.

3.1.2. Bias of simulated extreme precipitation events in the recent period. To quantitatively evaluate the differences in summer climate extremes between models and observations, as well as intermodel variation, we compared the extreme events in terms of their intensity, duration and frequency, represented by the mean bias of R95P, CDD, and PDF, respectively.

Intensity (R95P). Mean biases (simulation minus observation) for summer (June-July-August) R95P between models and observation are presented in Fig. 3. The bias distributions of PRCPTOT showed a similar spatial pattern in spite of a larger bias than R95P, indicating the dominant contribution of heavy events to the total precipitation amount. All models overestimated precipitation over northeast China and underestimated precipitation over the Taklimakan Desert north of the Kunlun Mountains. Generally, there were 4 bias distributions apart from these common features: one such pattern was for RegCM3 (Fig. 3c) and ECHAM5 (Fig. 3a). Both showed predominantly less precipitation (dry bias) over the middle and lower reaches of the Yangtze River basin in South China, the eastern portion of the Indochina Peninsula, as well as northern India. 
SDII

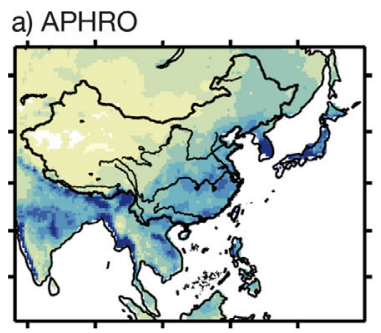

d) $\mathrm{RegCM} 3$

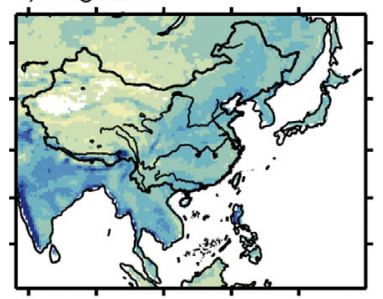

b) ECHAM5

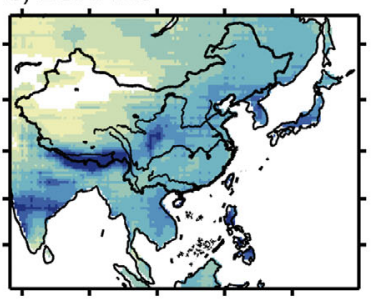

e) WRF

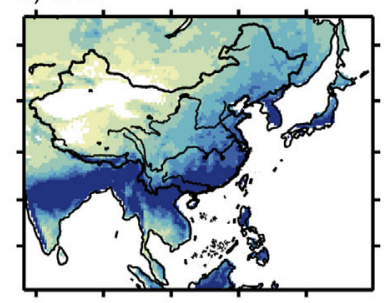

c) RMME

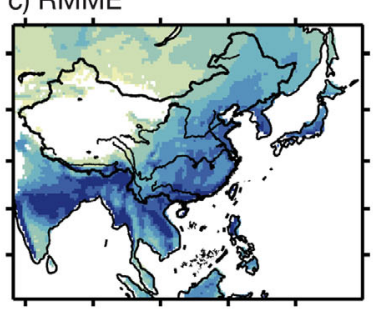

f) SNURCM

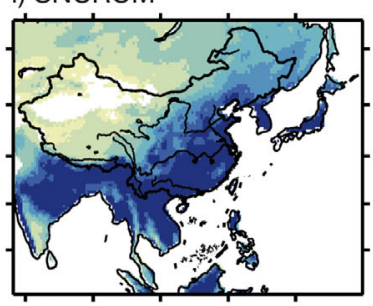

Precipitation

$\left(\mathrm{mm} \mathrm{d}^{-1}\right)$

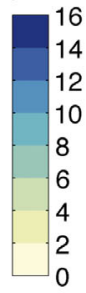

g) GRIMs

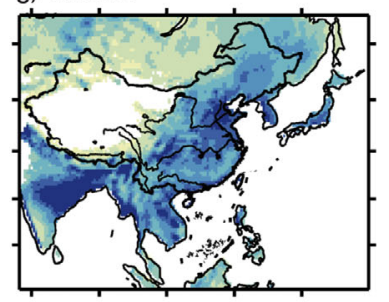

R95P

a) APHRO

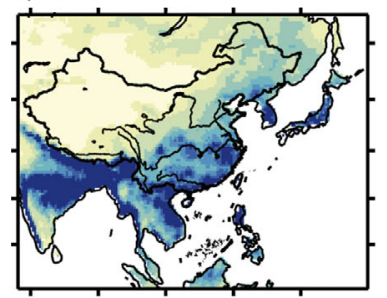

d) RegCM3

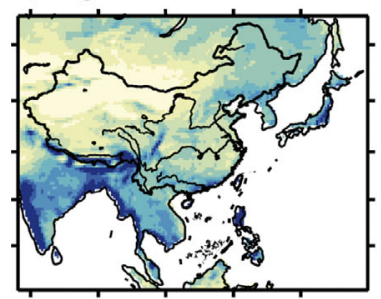

b) ECHAM5

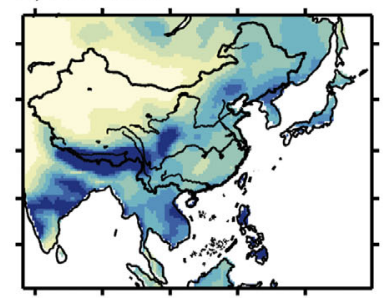

e) WRF

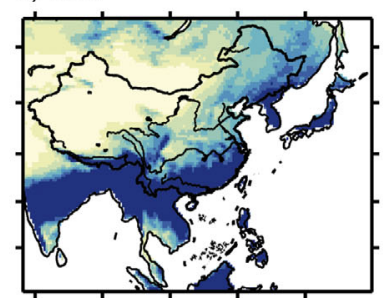

c) RMME

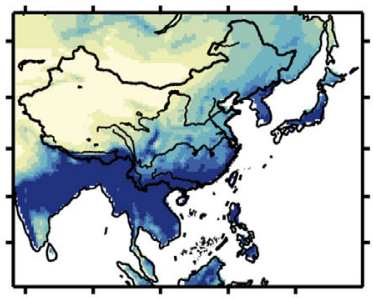

f) SNURCM

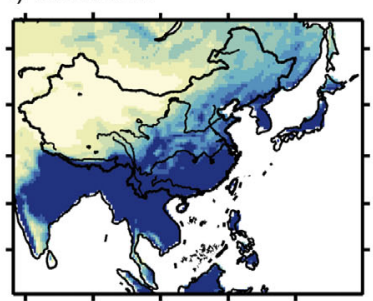

Precipitation $\left(\mathrm{mm} \mathrm{d}^{-1}\right)$

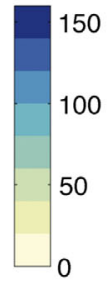

g) GRIMs

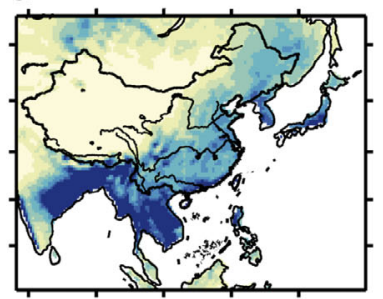

Fig. 2. Climatological average of summer (June-July-August) SDII (upper panels) and R95P (bottom panels) from (a) APHRO observation data and (c-g) RCM simulations together with their (b) driving GCM ECHAM5 during 1982-2000

Meanwhile, RegCM3 and ECHAM5 simulated more precipitation over the southern part of the Tibetan Plateau, which is consistent with the findings of Zhao \& Fu (2010). By comparison, SNURCM showed general overestimation of R95P (>50\%), except in the Tarim Basin in northwest China, northwest India, and the eastern edge of the Indochina Peninsula. GRIMs showed a different pattern from the others, with a widespread negative bias. As a mean of the 4 models, the regional multi-model ensemble (RMME) alleviated the large negative bias over southern China that was simulated by RegCM3 and the widespread positive bias that was simulated by SNURCM. The WRF model demonstrated a similar pattern to the RMME, both of which simulated more precipitation over southern India, the eastern portion of the Indochina Peninsula, and northeast China. However, they underestimated the precipitation over northern India, the southern boundary of the Himalaya Mountains as well as the middle and lower Yangtze River basin.

Duration $(C D D)$. Apart from the intensity of extreme precipitation, we also quantified the simulated summer extreme events from a persistence viewpoint. Mean bias analyses of the duration indices for CDD were conducted (Fig. 4). All models overestimated CDD by $\geq 10 \%$ over most of China. In particular, all RCMs simulated a uniform, overwhelmingly longer duration of dry days (>30\%) over the Tarim Basin in northwest China, which is 
a) ECHAM5

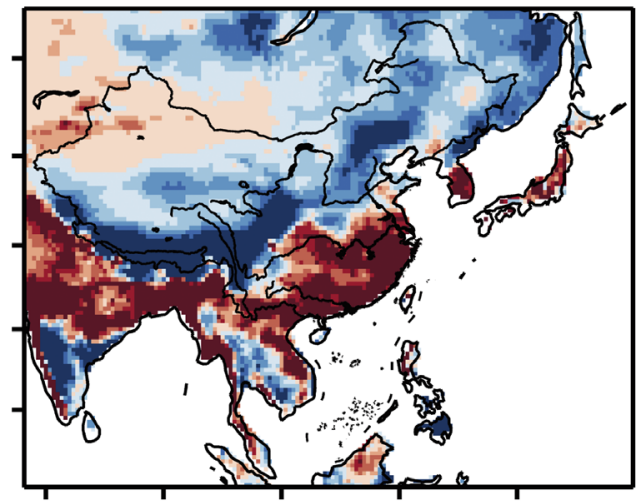

c) RegCM3

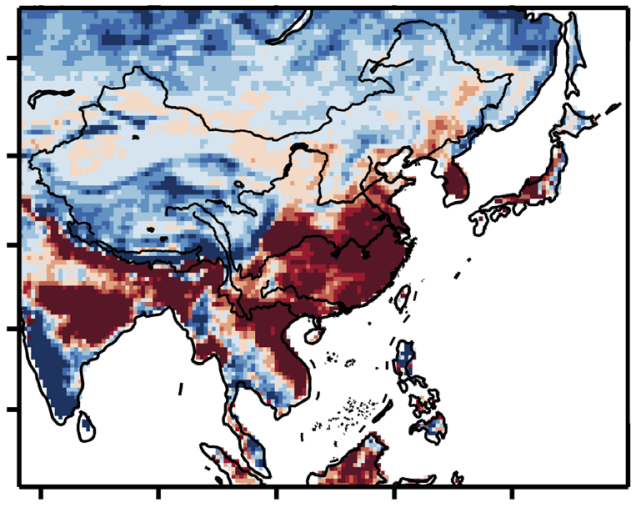

e) SNURCM

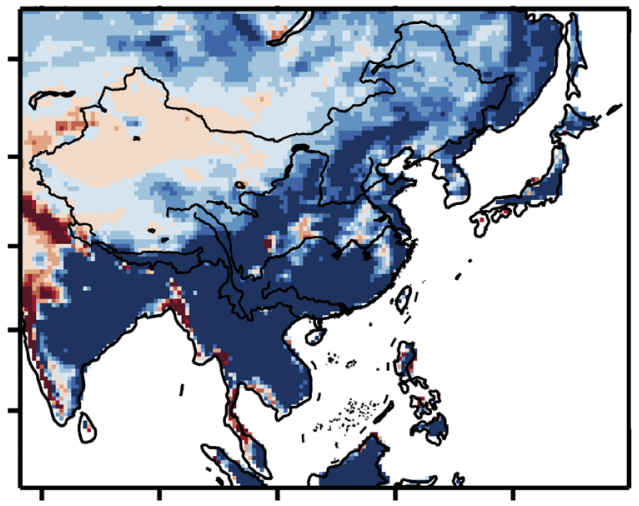

b) RMME

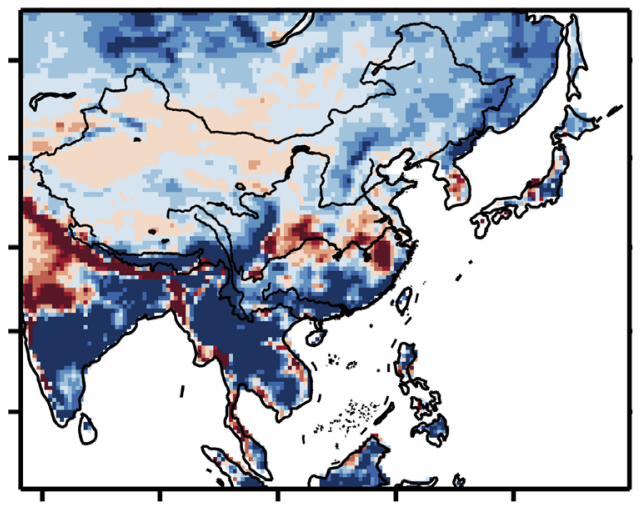

d) WRF

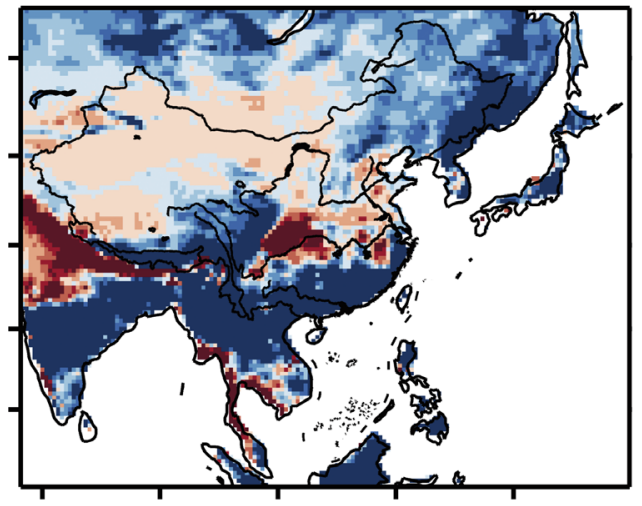

f) GRIMs

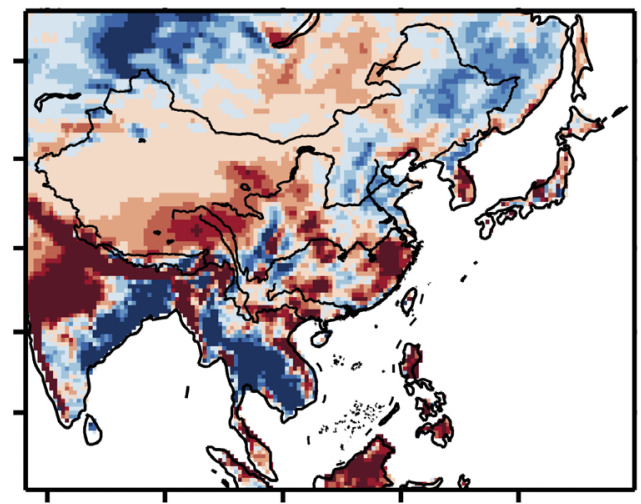

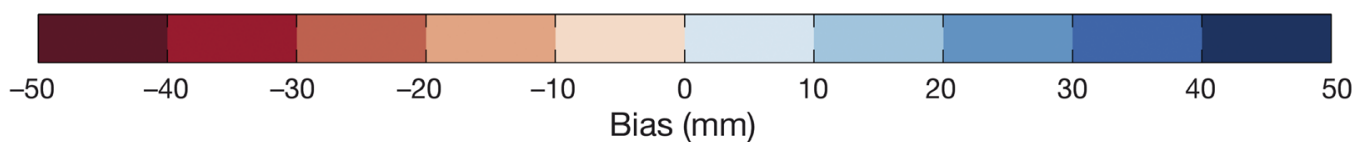

Fig. 3. Absolute bias of summer (June-July-August) R95P between model simulations and observations during 1982-2000

consistent with the driving GCM ECHAM5. There were also some differences among individual models. For example, ECHAM5 underestimated CDD over northeast China as well as the Tibetan Plateau area. RegCM3 also simulated shorter CDD than that in the APHRO observations over the west Tibetan Plateau, but it overestimated CDD over northeast China. For the other $3 \mathrm{RCMs}$, both WRF and GRIMs underestimated CDD over the eastern area of northeast China, while SNURCM overall showed more CDDs than observed values. The RMME offset the extremely large positive/negative CDD biases of the different RCM simulations, resulting in a relatively small bias. A typical region was over the Tibetan Plateau, where RegCM3 simulated fewer CDDs while WRF and GRIMs simulated more. 
a) ECHAM5

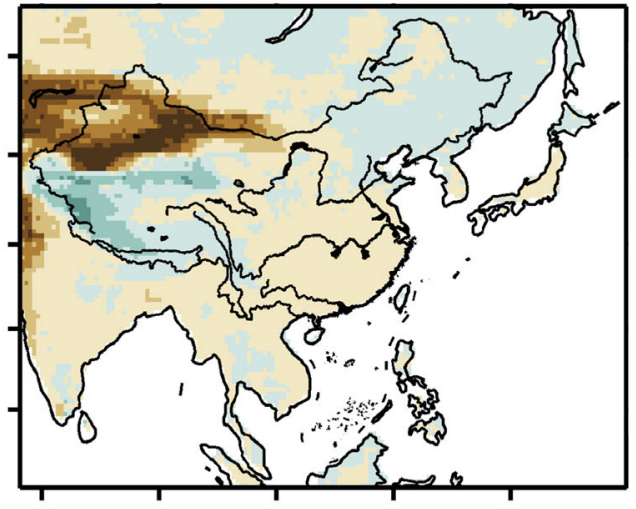

c) $\mathrm{RegCM} 3$

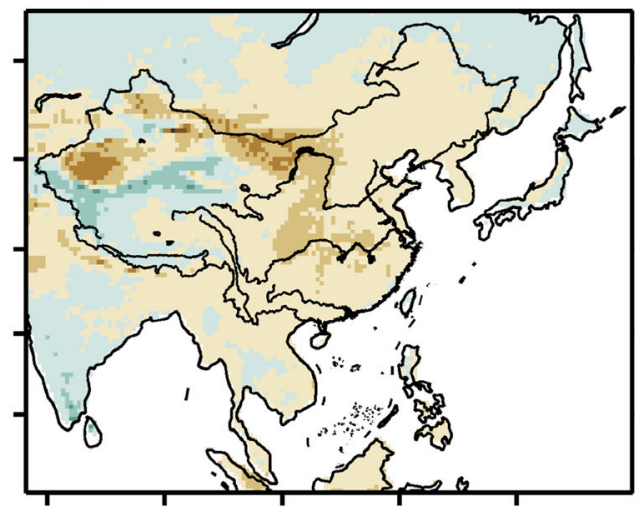

e) SNURCM

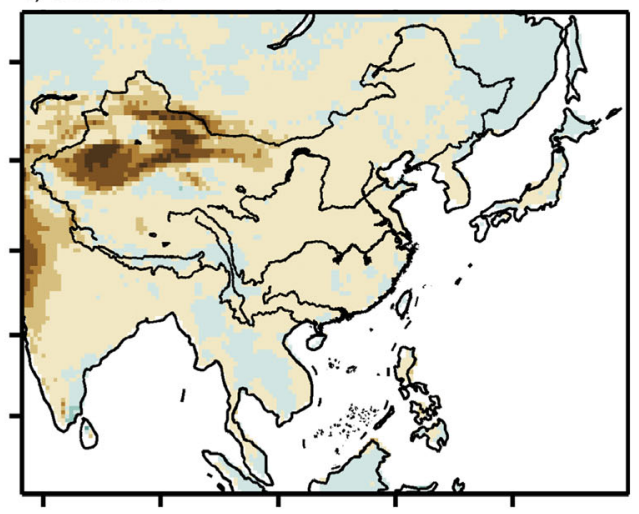

b) $\mathrm{RMME}$

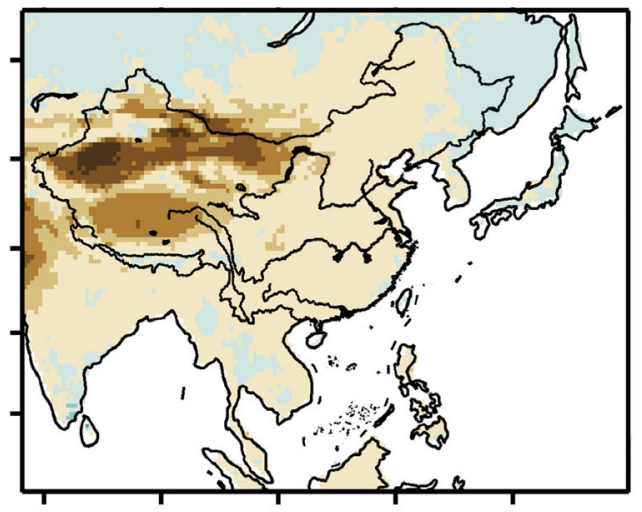

d) WRF

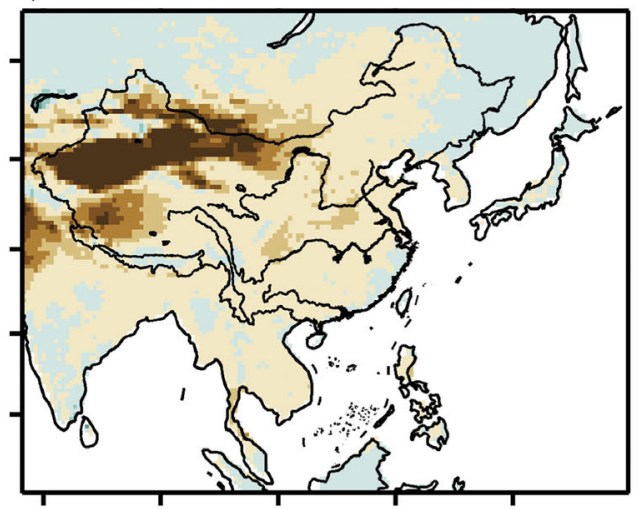

f) GRIMs

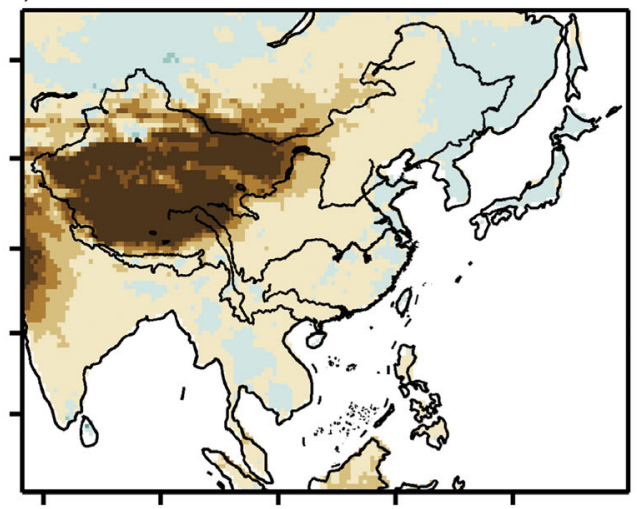

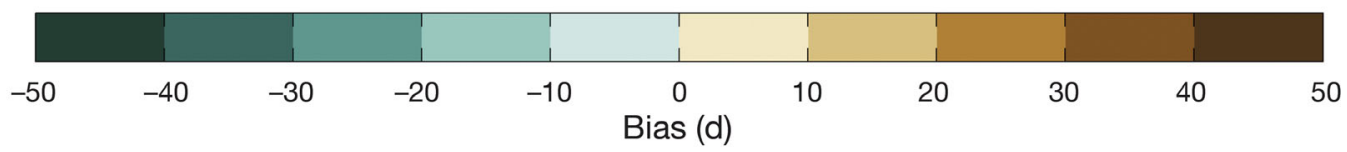

Fig. 4. Absolute biases (model-observation) of summer (June-July-August) maximum consecutive dry days (CDD) between model simulations and observations

Frequency of occurrence (PDF). To examine the bias distribution of the simulated whole precipitation spectra, the model-simulated PDF was compared to APHRO observations over 4 sub-regions, as outlined in Fig. 1. The 4 regions were divided according to their typical climate character. North China (NC) has a relatively dry climate in winter and spring, influ- enced by cold airflow from Siberia, and more precipitation, largely brought (in summer) by a mesoscale convective system and weakened monsoons. The mid-lower Yangtze River basin (MYR) and southeast China (SEC) are wet regions impacted by monsoon and frequently occurring typhoons from the northwest Pacific Ocean. Moreover, MYR also experiences 

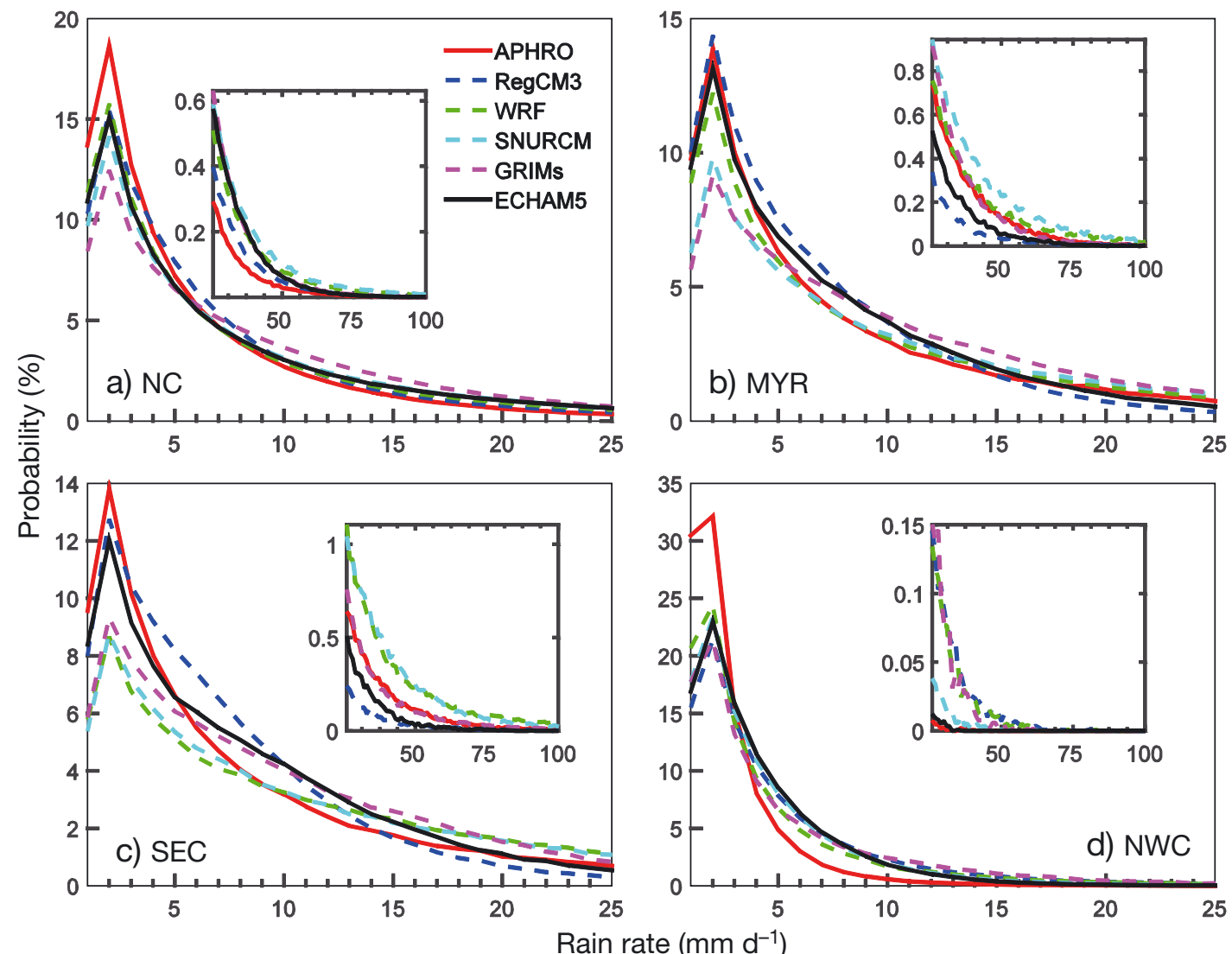

Fig. 5. Frequency of occurrence for the whole precipitation spectra in summer (June-July-August) over 4 sub-regions in China: (a) north China (NC); (b) mid-lower Yangtze River basin (MYR); (c) southeast China (SEC); (d) northwest China (NWC). Spectra with daily precipitation amounts of $>25 \mathrm{~mm} \mathrm{~d}^{-1}$ are displayed as small add-in figures in each subplot

the East Asian rainy season (commonly called the Meiyu rain) during the late spring and early summer, which is caused by precipitation along a persistent stationary front known as the Meiyu front. Northwest China (NWC) has a representatively dry climate with little or even no precipitation, as less water vapor can be transported here.

Frequencies of occurrence for precipitation spectra are shown in Fig. 5. All models simulated less light precipitation $\left(r<7.0 \mathrm{~mm} \mathrm{~d}^{-1}\right)$ and more moderate and heavy precipitation $\left(>7.0 \mathrm{~mm} \mathrm{~d}^{-1}\right)$ than observations over NC. Among the different models, GRIMs simulated the lowest light precipitation frequency. Over the MYR, the WRF model performed best in simulating the frequency of occurrence. RegCM3 simulated a little more light and moderate precipitation $\left(<15 \mathrm{~mm} \mathrm{~d}^{-1}\right)$ and less heavy precipitation $(>15 \mathrm{~mm}$ $\left.\mathrm{d}^{-1}\right)$. Conversely, other RCMs underestimated light precipitation $\left(<7.0 \mathrm{~mm} \mathrm{~d}^{-1}\right)$ and overestimated heavy precipitation. The driving model ECHAM5 simulated less light and heavy precipitation and more medium precipitation. The results for SEC were similar to those for the MYR. This was consistent with the observed bias distribution in Fig. 3. In NWC, all models underestimated light precipitation $\left(<3.0 \mathrm{~mm} \mathrm{~d}^{-1}\right)$ and overestimated moderate and heavy precipitation $\left(>4.0 \mathrm{~mm} \mathrm{~d}^{-1}\right)$. As this region is located far away from the ocean, the dominant precipitation was less than $10 \mathrm{~mm} \mathrm{~d}^{-1}$. The frequency of light precipitation at $2.0 \mathrm{~mm} \mathrm{~d}^{-1}$ reached $20 \%$ in the models and $30 \%$ in observed data.

3.1.3. Taylor diagram. To obtain an overall impression of the capacity of the 4 RCMs, the driving GCM and the ensemble average RMME to simulate extreme precipitation intensity and persistence, a Taylor diagram was constructed (Fig. 6) to illustrate the pattern correlations and normalized root mean square error (RMSE) between simulations and observations. Generally, all models simulated the intensity indices SDII and R95P better than the duration index $\mathrm{CDD}$, showing larger pattern correlation coefficients and smaller deviations and RMSE. Of all the models, GRIMs performed the best, and the RCM ensemble RMME also showed a substantially higher pattern correlation in simulating R95P and SDII. The WRF model showed relatively large standardized devia- 


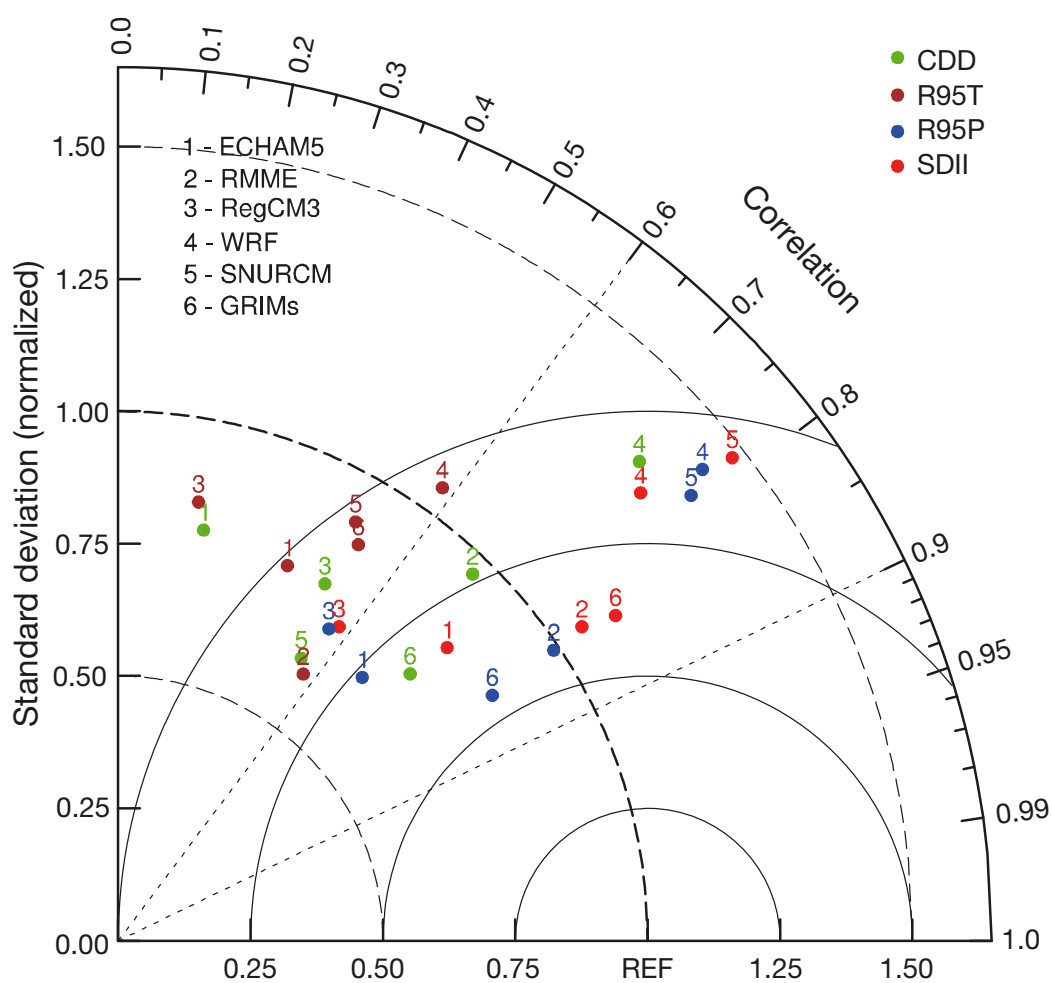
tween the APHRO data and individual models, as well as their driving GCM and ensemble averages for the summer (June-July-August) extremes, with CDD; R95P, R95T, and SDII. REF: model has the same standard deviation and RMSE as observation (APHRO). Concentric curved solid lines: normalized RMSE between model and APHRO; straight dashed lines: spatial pattern correlation
Fig. 6. Standard deviations and spatial pattern correlation coefficients be-

used to test the significance of difference between future and recent variability. Grid-boxes with significant changes that passed the F-test are labeled with black dots.

Overall, all models projected the complex spatial patterns of changing R95P with mixed small-scale negative and positive changes. ECHAM5 demonstrated a significant increase over southern China (south of the Yangtze River), the Indochina Peninsula, western India, and Japan, while a decreasing tendency was projected over northwest China and western Mongolia (Fig. 7a). The RMME showed a widespread increase in R95P. It also projected the same decrease in R95P over the area north of the Yellow River as ECHAM5, but with a smaller magnitude and domain (Fig. 7b). For the other individual RCMs, RegCM3 showed the opposite change in summer R95P to ECHAM5, projecting a prominent decrease over the middle and lower Yangtze River basin, the Indochina Peninsula and India (Fig. 7c). WRF and GRIMs showed little significant change over southeastern China (Fig. 7d,f). A consistent decrease in R95P over the area north of the Yellow

tions in spite of a high correlation ( 0.7 to 0.8$)$. In comparison, few individual regional models could accurately reproduce the spatial pattern of CDD and several showed a small pattern correlation $(<0.6)$. The RCM ensemble RMME and WRF performed better than the others in simulating CDD.

\subsection{Projected change of extreme precipitation in the future}

3.2.1. R95P. The projected changes in summer R95P for the period of 2052 to 2070 under the A1B emission scenario relative to the recent period of 1982 to 2000 are shown in Fig. 7. A paired difference Student's $t$-test for a hypothesis of zero difference was applied to examine the statistical significance of change between the future and recent simulated seasonal precipitation amount at a $95 \%$ confidence level. The results did not show a significant change in the mean value. Considering the large inter-annual variability, an F-test was also
River was well simulated by all models (Fig. 7).

3.2.2. CDD. In addition to the extreme heavy precipitation indicated by R95P, changes in summer CDD under an A1B scenario were also investigated (Fig. 8). Overall, most models projected prolonged and RegCM3. According to the driving GCM ECHAM5, there will be more CDDs in the future over most of China, except over southeastern China. Another region showing decreased CDD was the Indochina Peninsula (Fig. 8a). The RMME projected a prominent increase in CDD over most of China except for the Tibetan Plateau and northwest India (Fig. 8b). A widespread increase in CDD over southern China (south of the Yangtze River) was projected by the RMME and was not well captured by ECHAM5. Regarding inter-model differences among the 4 individual RCMs, RegCM3 projected a widespread increasing trend for CDD over China. Substantial increases in CDD were projected to occur over India and the Indochina Peninsula. In China, it predicted an increase in CDD along the middle and dry spells over eastern China, except for ECHAM5 
a) ECHAM5

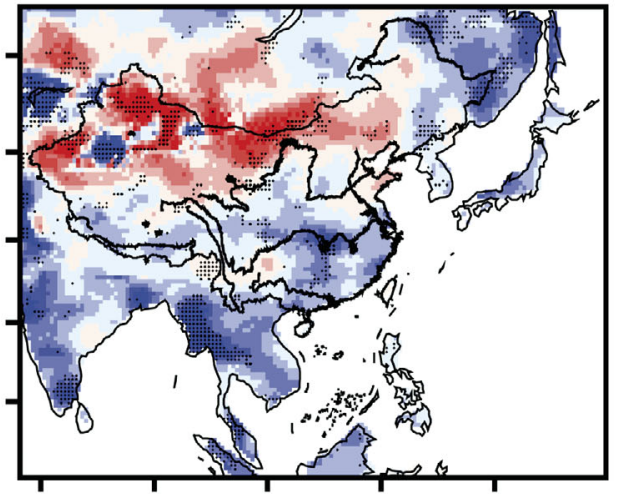

c) $\operatorname{RegCM} 3$

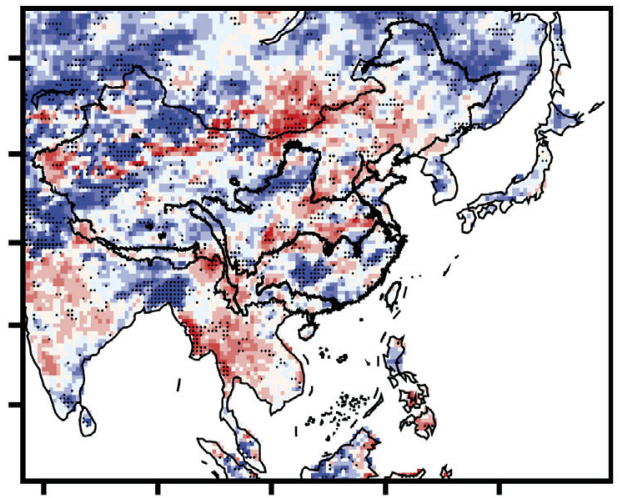

e) SNURCM

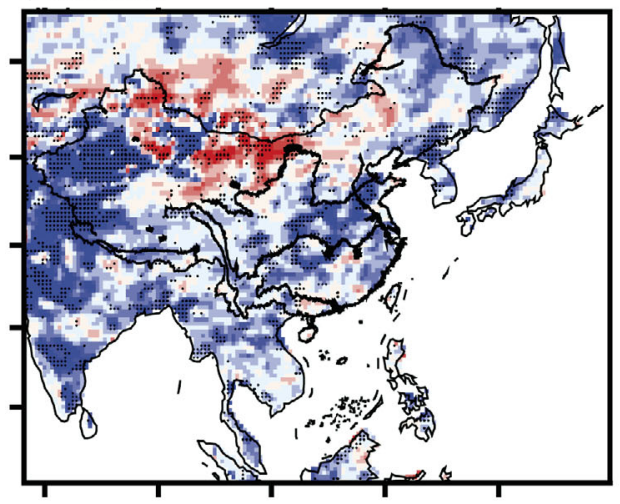

b) RMME

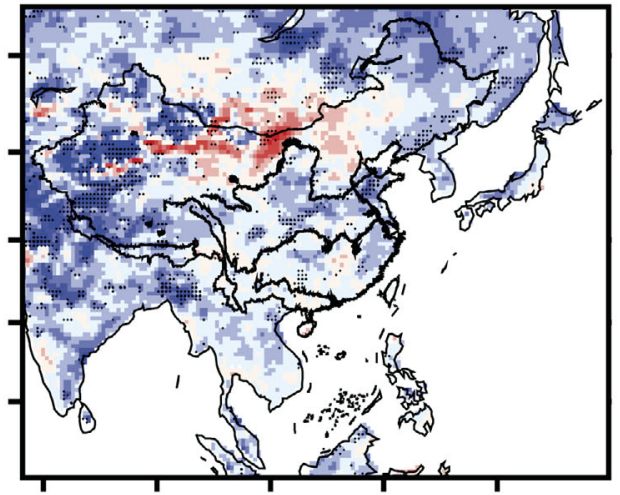

d) WRF

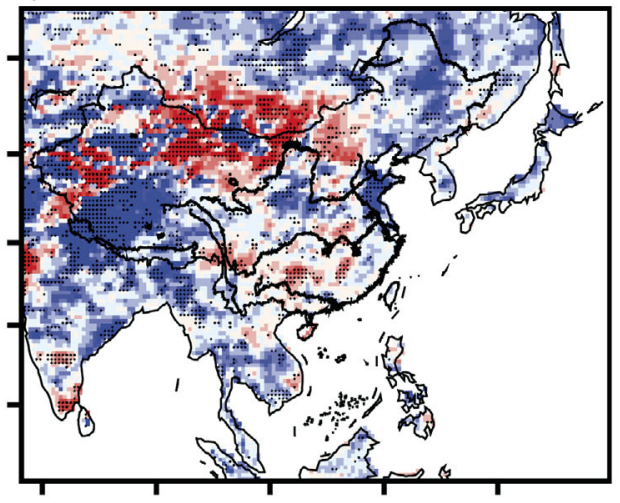

f) GRIMs

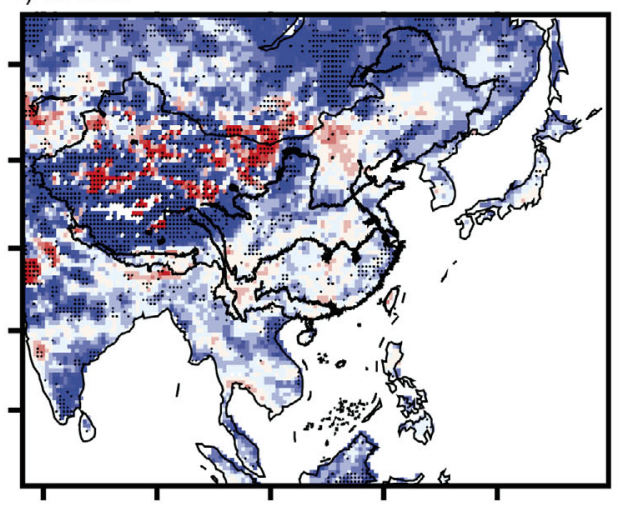

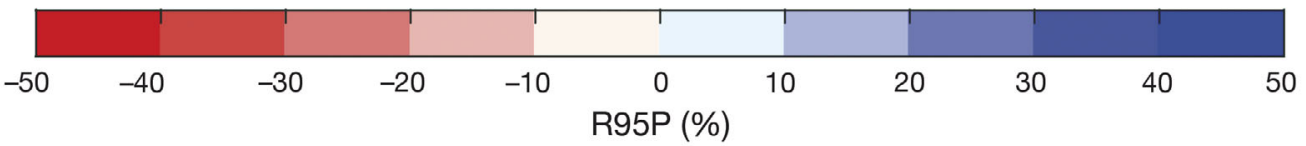

Fig. 7. Percentage change in summer (June-July-August) R95P under the A1B emission scenario (2052 to 2070) compared to a recent time period (1982 to 2000). Grid-boxes with changes in variability that were statistically significant at the $95 \%$ confidence level ( $F$-test) are indicated by black dots

lower reaches of the Yangtze River (Fig. 8c). The WRF model projected a widespread increase in CDD over most of China, despite the decrease over the Tibetan Plateau region and northern Mongolia (Fig. 8d). SNURCM projected an increasing trend for CDD over the Indochina Peninsula and southwest China (Fig. 8e), which was consistent among the regional models but the opposite of the GCM ECHAM5 result. GRIMs projected a substantial increase over eastern China, the Tarim Basin, southeastern India and the western edge of the Indochina Peninsula. Over the Tibetan Plateau, CDD was projected to decrease (Fig. 8f). 
a) ECHAM5

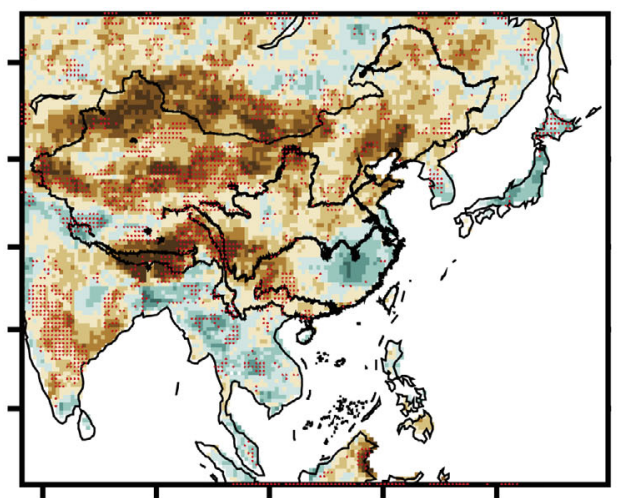

c) $\mathrm{Reg} \mathrm{CM} 3$

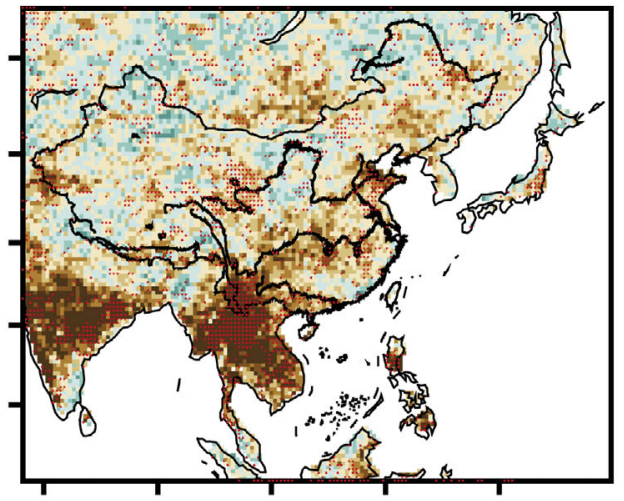

e) SNURCM

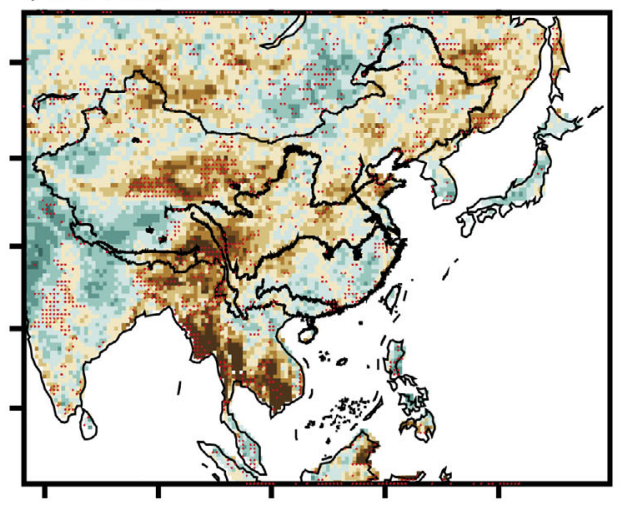

b) RMME

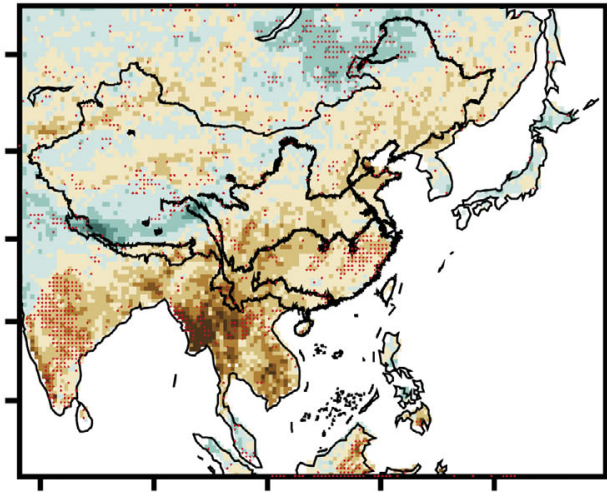

d) WRF

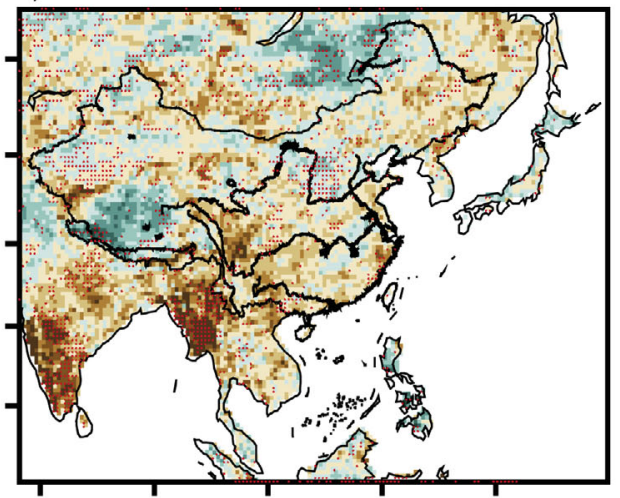

f) GRIMs

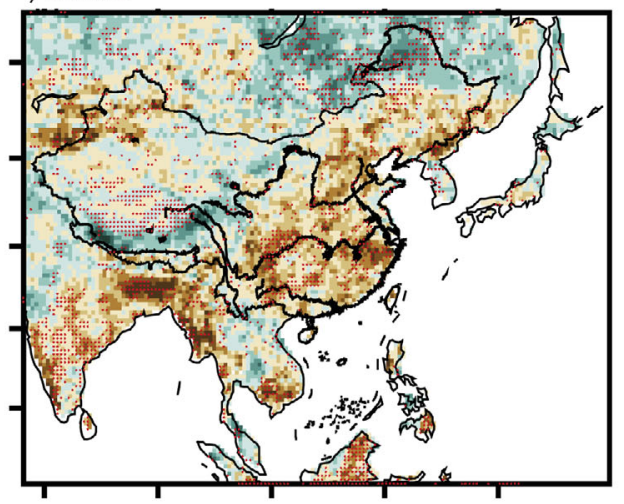

$30 \quad 40 \quad 50$

$\operatorname{CDD}(\%)$

Fig. 8. Percentage change in summer (June-July-August) CDD (unit: \%) under the A1B emission scenario (2052-2070) compared to a recent time period (1982-2000). Grid-boxes with changes of variability that were statistically significant at the $95 \%$ confidence level ( $F$-test) are indicated by red dots

\subsection{Uncertainties associated with observations and large-scale circulation in models}

As atmospheric processes that induce extreme precipitation or long-term dry conditions were not necessarily matched to each other among all models, the composite analysis of water vapor transport and extreme events among the 5 models was quite challenging. To make the explanations easier, we simply analyzed the background field on a monthly scale. As extreme precipitation made a substantial contribution to total precipitation (Zou \& Zhou 2013), it showed generally the same spatial distribution (Zhao \& Fu 2010). The monthly mean values for large-scale 

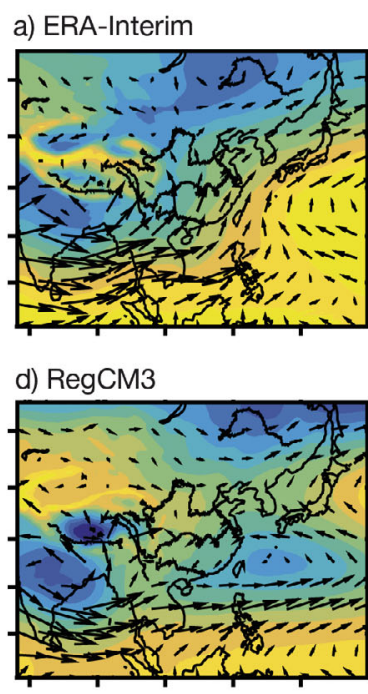
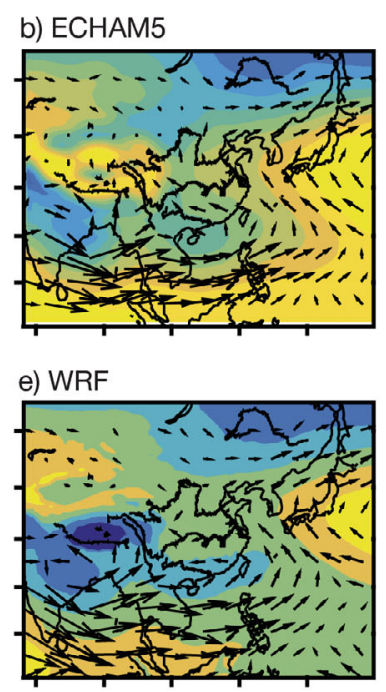

c) RMME

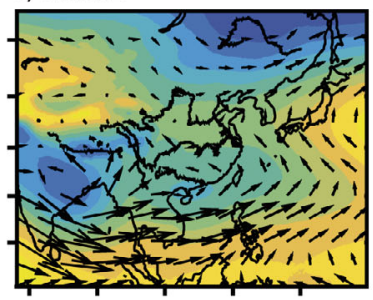

f) SNURCM

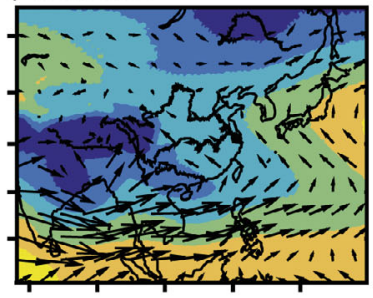

850 hpa geopotential height (gpm)
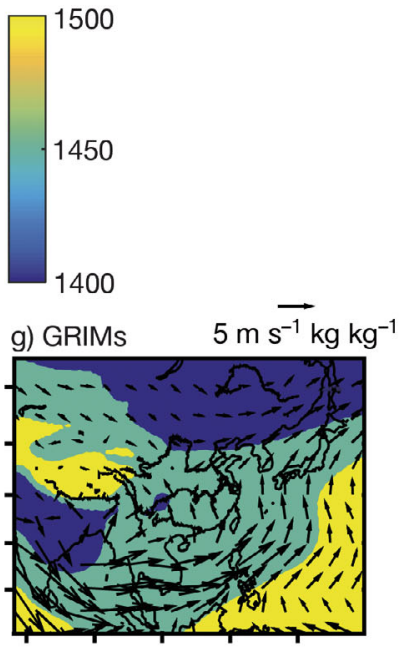

Fig. 9. Climatological average of summer (June-July-August) water vapor transport field, overlapped (vector, $\mathrm{m} \mathrm{s}^{-1} \mathrm{~kg} \mathrm{~kg}^{-1}$ ) with geopotential height at a $850 \mathrm{hPa}$ level, from 1982 to 1999. gpm: geopotential meters

circulation could be used to explain the detected extreme precipitation bias between model simulations and observations. Large-scale circulations, indicated by water vapor transport at the $850 \mathrm{hPa}$ level, were analyzed. Here, we compared the large-scale circulation from model simulations and reanalysis data from the European Research Centre (ERAInterim).

Fig. 9 shows the composite climatology distribution of summer (June-July-August) water transport and geopotential height at the $850 \mathrm{hPa}$ level, derived from ERA-Interim reanalysis data and RMIP model simulations during the period from 1980 to 1999. A Western Pacific subtropical high (WPSH) detected by ECHAM5 and the RMME was consistent with past studies (Zhao \& Fu 2010). There were some differences between the simulated WPSH and the reanalysis dataset. Compared to the ERA-Interim data, both ECHAM5 and the RMME showed a northeastward shift of the center of WPSH in the northwestern Pacific. Accompanying the high pressure were clockwise southerly and southeasterly winds, which bring plentiful water vapor from the western Pacific and Indian Oceans (Fig. 9b,c). RegCM3 simulated a lowpressure center over the western Pacific, which resulted in less water vapor transport to southern China (Fig. 9d). This could partly explain why less precipitation was detected by RegCM3. GRIMs performed in a different manner, with no typical high/ low pressure centers, despite a pressure gradient directed from high pressure over the Pacific Ocean down toward inland Eurasia (Fig. 9f).

\section{DISCUSSION AND CONCLUDING REMARKS}

In this study, the performances of 4 RCMs participating in the RMIP project, together with their driving GCM and the ensemble average RMME, were evaluated for their ability to simulate summer extreme precipitation over East Asia from 1982 to 2000. The projected future changes under the A1B emission scenario during the period from 2052 to 2070 were then investigated. The results can be summarized as follows:

(1) All models had certain abilities in reproducing the basic characteristics of regional details, such as the geographic distribution of both total and heavy precipitation in China. The majority of models could capture the 'South Flood and North Drought' distribution of precipitation in China associated with summer monsoons. Bias analysis showed that RegCM3 and the driving GCM ECHAM5 underestimated R95P over southern China, northern India and the eastern Indochina Peninsula. This bias in the level of extreme precipitation corresponded with the difference in observed frequency of occurrence. Both models underestimated the occurrence of heavy precipitation over southern China. Similar results have also been reported in other studies using RegCM3 (Zou \& Zhou 2013) and RegCM4 (Gu et al. 2012). It is worth noting that RegCM3 is the only regional model performed without nudging, but internal nudging could increase mesoscale variability and add value to the GCM (Feser et al. 2011, Otte et al. 2012). We speculate that regional models without nudging may 
inherit more bias from the driving GCM compared to those with nudging.

When regarding the precipitation bias alone, it was hard to decide which model performed best due to the substantial variation in their ability from one region to another. For example, the GRIMs model showed a prominently dry bias in precipitation over western China, including the Tibetan Plateau. However, it had a relatively high pattern correlation coefficient. Taylor diagram analysis also showed that the RMME performed better overall than the individual models, indicating that multi-model ensemble averages could effectively improve simulation performance. This is because ensemble means can offset some negative and positive biases through multimodel averaging. In addition, the RCMs performed better in simulating extreme precipitation intensity than duration character.

(2) In the future projections, the majority of the models projected an increase in summer R95P over the East Asian land area, which was consistent with that of the mean precipitation SDII, implying a large contribution of heavy events to total precipitation. The projected trend of R95P was consistent with many past studies of RCMs (Gao et al. 2002, Zhang et al. 2006) and GCMs (Giorgi et al. 2001, Chen \& Sun 2009, Wang et al. 2012). According to the ECHAM5 model, extreme precipitation (R95P) will increase significantly over relatively wet regions, while dry spells will increase particularly over dry regions in the future under an A1B emission scenario (Sillmann \& Roeckner 2008). A widespread increased in CDD was projected in the summer by the ECHAM5 and SNURCM models, except for southeastern China. This means that both extreme precipitation intensity and CDD could increase simultaneously in the future under an A1B emission scenario and under global warming conditions.

This study provides comprehensive evaluations of the capability of 4 RMIP RCMs and their ensemble average RMME to simulate present extreme precipitation and project future changes. Although comparisons among models provided useful information about their deficits and advantages, in-depth analyses of why models performed well in one region and less well in others, as well as of the differences among individual models, are needed to improve our understanding of the uncertainties in precipitation simulation.

Acknowledgements. This research was supported by the Asia-Pacific Network for Global Change (APN) under project number ARCP2010_04CMY_WANG. This research was also conducted with the support of the National Basic
Research and Development (973) Program of China under grant number 2011CB952004, the Jiangsu Collaborative Innovation Center for Climate Change, and the Korea Meteorological Administration Research and Development Program under grant number CATER 2012-3084. The authors also thank the International Project Office (IPO) of the Monsoon Asia Integrated Study (MAIRS) for its support and assistance in the completion of this study. The contributions of Y.Q. and Y.G. to this study were supported by the US Department of Energy's Office of Science as part of the Regional and Global Climate Modeling Program. The Pacific Northwest National Laboratory was operated for the Department of Energy by the Battelle Memorial Institute under contract number DE-AC05-76RL01830.

\section{LITERATURE CITED}

Bengtsson L, Hodges KI, Esch M, Keenlyside N, Kornblueh L, Luo JJ, Yamagata T (2007) How may tropical cyclones change in a warmer climate? Tellus, Ser A, Dyn Meterol Oceanogr 59:539-561

Chen H, Sun J (2009) How the 'best' models project the future precipitation change in China. Adv Atmos Sci 26: 773-782

Christensen JH, Carter TR, Rummukainen M, Amanatidis G (2007) Evaluating the performance and utility of regional climate models: the PRUDENCE project. Clim Change 81:1-6

$>$ Feng L, Zhou TJ, Wu B, Li T, Luo JJ (2011) Projection of future precipitation change over China with a highresolution global atmospheric model. Adv Atmos Sci 28: 464-476

Feser F, Rockel B, von Storch H, Winterfeldt J, Zahn M (2011) Regional climate models add value to global model data: a review and selected examples. Bull Am Meteorol Soc 92:1181-1192

- Fu CB, Wang SY, Xiong Z, Gutowski WJ and others (2005) Regional climate model intercomparison project for Asia. Bull Am Meteorol Soc 86:257-266

Gao XJ, Zhao ZC, Giorgi F (2002) Changes of extreme events in regional climate simulations over East Asia. Adv Atmos Sci 19:927-942

Gao XJ, Xu Y, Zhao ZC, Pal JS, Giorgi F (2006) On the role of resolution and topography in the simulation of East Asia precipitation. Theor Appl Climatol 86:173-185

Gao XJ, Shi Y, Song R, Giorgi F, Wang Y, Zhang D (2008) Reduction of future monsoon precipitation over China: comparison between a high resolution RCM simulation and the driving GCM. Meteorol Atmos Phys 100:73-86

Gao XJ, Shi Y, Zhang DF, Wu J, Giorgi F, Ji ZM, Wang YG (2012) Uncertainties in monsoon precipitation projections over China: results from two high-resolution RCM simulations. Clim Res 52:213-226

> Gao Y, Xue Y, Kang HS, Waliser D (2011) Assessment of dynamic downscaling of the extreme rainfall over East Asia using a regional climate model. Adv Atmos Sci 28: 1077-1098

Giorgi F, Mearns LO (1999) Introduction to special section: Regional climate modeling revisited. J Geophys Res Atmos 104:6335-6352

Giorgi F, Whetton PH, Jones RG, Christensen JH and others (2001) Emerging patterns of simulated regional climatic changes for the 21st century due to anthropogenic forcings. Geophys Res Lett 28:3317-3320 
Giorgi F, Jones C, Asrar GR (2009) Addressing climate information needs at the regional level: the CORDEX framework. WMO Bull 58:175-183

Gu H, Wang G, Yu Z, Mei R (2012) Assessing future climate changes and extreme indicators in east and south Asia using the RegCM4 regional climate model. Clim Change 114:301-317

Han Z, Zhou T (2012) Assessing the quality of APHRODITE high-resolution daily precipitation dataset over contiguous China. Chin J Atmos Sci 36:361-373

Hong SY, Park H, Cheong HB, Kim JEE and others (2013) The global/regional integrated model system (GRIMs). Asia-Pac J Atmospheric Sci 49:219-243

Ji Z, Kang S (2015) Evaluation of extreme climate events using a regional climate model for China. Int J Climatol 35:888-902

Kim J, Waliser DE, Mattmann CA, Goodale CE and others (2014) Evaluation of the CORDEX-Africa multi-RCM hindcast: systematic model errors. Clim Dyn 42: 1189-1202

Lang X, Sui Y (2013) Changes in mean and extreme climates over China with a $2^{\circ} \mathrm{C}$ global warming. Chin Sci Bull 58: 1453-1461

Lee MH, Ho CH, Kim J, Song CK (2012) Assessment of the changes in extreme vulnerability over East Asia due to global warming. Clim Change 113:301-321

Lee DK, Cha DH, Jin CS, Choi SJ (2013) A regional climate change simulation over East Asia. Asia-Pac J Atmospheric Sci 49:655-664

Leung LR, Qian Y, Bian XD, Washington WM, Han JG, Roads JO (2004) Mid-century ensemble regional climate change scenarios for the western United States. Clim Change 62:75-113

Liu SC, Fu CB, Shiu CJ, Chen JP, Wu FT (2009) Temperature dependence of global precipitation extremes. Geophys Res Lett 36:L17702, doi:10.1029/2009GL040218

Mearns LO, Gutowski W, Jones R, Leung R, McGinnis S, Nunes A, Qian Y (2009) A regional climate change assessment program for North America. Eos Trans AGU 90:311, doi:10.1029/2009EO360002

Niu X, Wang S, Tang J, Lee DK and others (2015) Multimodel ensemble projection of precipitation in eastern China under A1B emission scenario. J Geophys Res Atmos 120:9965-9980

Otte TL, Nolte CG, Otte MJ, Bowden JH (2012) Does nudging squelch the extremes in regional climate modeling? J Clim 25:7046-7066

Pal JS, Giorgi F, Bi X, Elguindi N and others (2007) Regional climate modeling for the developing world: the ICTP RegCM3 and RegCNET. Bull Am Meteorol Soc 88: 1395-1409

Park JH, Oh SG, Suh MS (2013) Impacts of boundary conditions on the precipitation simulation of RegCM4 in the CORDEX East Asia domain. J Geophys Res Atmos 118: 1652-1667

Park C, Min SK, Lee D, Cha DH and others (in press) Evaluation of multiple regional climate models for summer climate extremes over East Asia. Clim Dyn, doi: 10.1007/s00382-015-2713-z

Qian Y, Leung LR (2007) A long-term regional simulation

Editorial responsibility: Filippo Giorgi,

Trieste, Italy and observations of the hydroclimate in China. J Geophys Res 112:D14104, doi:10.1029/2006JD008134

Roeckner E, Bäuml G, Bonaventura L, Brokopf R and others (eds) (2003) The atmospheric general circulation model ECHAM5. I. Model description. Report No. 349. Max Planck Institute for Meteorology, Hamburg

> Sillmann J, Roeckner E (2008) Indices for extreme events in projections of anthropogenic climate change. Clim Change 86:83-104

Skamarock WC, Klemp JB, Dudhia J, Gill DO, Barker DM, Wang W, Powers JG (2005) A description of the advanced research WRF version 2. NCAR Technical Report, NCAR, Boulder, CO

Trenberth KE, Dai A, Rasmussen RM, Parsons DB (2003) The changing character of precipitation. Bull Am Meteorol Soc 84:1205-1217

> Wang HJ, Sun JQ, Chen HP, Zhu YL and others (2012) Extreme climate in China: facts, simulation and projection. Meteorol Z 21:279-304

> Wu FT, Fu CB (2013) Change of precipitation intensity spectra at different spatial scales under warming conditions. Chin Sci Bull 58:1385-1394

Wu J, Gao XJ (2013) A gridded daily observation dataset over China region and comparison with the other datasets. Chin J Geophys 56:1102-1111 (in Chinese with English abstract)

> Wu J, Gao XJ, Xu YL, Pan J (2015) Regional climate change and uncertainty analysis based on four regional climate model simulations over China. Atmos Ocean Sci Lett 8: $147-152$

Xu JY, Shi Y, Gao XJ, Giorgi F (2013) Projected changes in climate extremes over China in the 21st century from a high resolution regional climate model (RegCM3). Chin Sci Bull 58:1443-1452

Yatagai A, Arakawa O, Kamiguchi K, Kawamoto H, Nodzu M, Hamada A (2009) A 44-year daily gridded precipitation dataset for Asia based on a dense network of rain gauges. SOLA 5:137-140

Yu E, Wang H, Sun J (2011) A quick report on a dynamical downscaling simulation over China using the nested model. Atmos Ocean Sci Lett 3:325-329

Zhai P, Sun A, Ren F, Liu X, Gao B, Zhang Q (1999) Changes of climate extremes in China. Clim Change 42:203-218

Zhang Y, Xu Y, Dong W, Cao L, Sparrow M (2006) A future climate scenario of regional changes in extreme climate events over China using the PRECIS climate model. Geophys Res Lett 33:L24702, doi:10.1029/2006GL027229

Zhao DM, Fu CB (2010) Comparisons of low-level circulation characteristics between ECHAM5/MPI-OM results and NCEP/NCAR re-analysis data in East Asia. Atmos Ocean Sci Lett 3:189-194

Zhou TJ, Wu B, Wang B (2009) How well do atmospheric general circulation models capture the leading modes of the interannual variability of the Asian-Australian monsoon? J Clim 22:1159-1173

Zou LW, Zhou TJ (2013) Near future (2016-40) summer precipitation changes over China as projected by a regional climate model (RCM) under the RCP8.5 emissions scenario: comparison between RCM downscaling and the driving GCM. Adv Atmos Sci 30:806-818

Submitted: April 24, 2015; Accepted: February 22, 2016

Proofs received from author(s): April 28, 2016 